\title{
Boi da Cara Preta: Transfiguração do Escravo, Humanização do Boi
}

Ivan Luiz Chaves Feijó

\section{Resumo:}

Tendo como ponto de partida a literatura de cordel nordestina, o texto analisa o ciclo do gado no sertão e a representação simbólica da figura do boi preto, como criatura mítica no qual o escravo é travestido. Podemos enxergar na saga do boi o drama dos africanos escravizados no Brasil, entoada por cantadores de origem ou de descendência africana, amalgamando realidade e imaginário. Tais expressões populares apontam o quanto foi conflituosa e complexa a transformação do africano em escravo para ser comprado no Brasil. O universo dos folhetos de cordel produziu imagens referentes à não aceitação dessa condição escrava, na figura do boi preto mágico, misterioso, veloz e livre, quebrando as correntes do confinamento e da submissão. Estas referências também são presentes nos cantos populares, nas cantigas de capoeira, nos cantos cerimoniais do candomblé e nas cantigas de ninar.

Palavra-chave: sertão nordestino - ciclo do gado - escravidão - literatura de cordel - cultura popular. 
Que já houve um tempo em que eles conversavam, entre si e com os homens, é certo e indiscutivel, pois que bem comprovado nos livros das fadas carochas. Mas, hoje em dia, agora, agorinha mesmo, aqui, ali, e em toda parte, poderão os bichos falar e serem entendidos, por você, por mim, por todo mundo, por qualquer um filho de Deus? !

O cordel fornece uma estrutura narrativa, uma linguagem e um código de valores que foram incorporados ao cotidiano da cultura nordestina. A produção do cordel aconteceu na prática da variação e reatualização de temas, imagens e símbolos enraizados numa práxis material coletiva, onde modelos narrativos foram repetidos e reconectados, ampliando sentidos. O discurso do cordel foi um difusor e cristalizador de determinadas projeções e enunciados que compuseram uma ideia de nordeste. Essa arte popular funcionou como um repositório de formas de expressão que foram e ainda são aproveitadas por outras produções culturais consideradas eruditas, como a literatura, o teatro e o cinema.

Sendo uma manifestação cultural do povo, o cordel ultrapassou a visão representativa para se tornar fazedor de linguagem e superar a noção de obra e autor. Ele produziu uma realidade relativa, que nasceu da memória popular, tendo como prática o entrelaçamento de acontecimentos das mais variadas temporalidades e espacialidades. Uma prática discursiva que inventou e reinventou a tradição, tornando-a presente e acima do tempo. Esta literatura popular possui uma estrutura narrativa que sempre foi manipulada de forma criativa pelo narrador, obedecendo a um protótipo fabular que pôde ser recoberto e remendado por enxertos e acréscimos individuais. O cordel é o retrato de um nordeste construído, por narrativas de ex-escravos, de pessoas sem sobrenome, com histórias ouvidas na infância, histórias que circulavam em toda a região, histórias de cangaceiros, de santos, coronéis, milagres, secas, de crimes, de mulheres perdidas, do sertão mítico, repositório de uma pureza perdida. ${ }^{2}$

A divulgada filiação do cordel nordestino à literatura de cordel portuguesa faz parte de um senso comum, como algo natural e até óbvio. Esta aparente obviedade assenta-se em pressupostos que se originam na relação colonial mantida entre Portugal e Brasil. O imaginário das elites construiu o "mito do colonizador" como um ser culturalmente superior e a quem cabe dar aos colonizados uma língua, uma religião, uma literatura, uma maneira de ver, pensar e organizar o mundo. Ao colonizado, tido como culturalmente vazio, só caberia receber, pois não teria nada para ofertar. A suposta troca poderia se dar em outro campo, na forma de produtos da natureza, por exemplo, como

I ROSA, João Guimarães. Conversa de bois in Sagarana. Editora Universal, I. ${ }^{\text {a }}$ edição. I946.

2 ALBUQUERQUE Jr., Durval Muniz. A invenção do nordeste e outras artes. Editora Massangana; Fundação Joaquim Nabuco; Cortez Editora. 200I. 
contrapartida à cultura europeia. Oferecia-se ouro, café e cana-de-açúcar em troca de poesia, livros e pinturas. Isto marcou profundamente a identidade nacional. Confundia-se poder político e econômico com capacidade criadora. Então, resolveu-se a questão da seguinte maneira: Como a produção artística da colônia era tida como algo menor, destituída de valor, postulou-se uma origem europeia para enobrecê-la, e com isso aumentar o status das tradições populares. O pressuposto é o de que os países centrais criavam e os demais imitavam. ${ }^{3}$

$\mathrm{Na}$ verdade, a literatura de cordel nordestina tem poucos elementos, em todo o seu processo, que lembrem o cordel português. Aqui no Brasil havia autores que viviam de comprar e vender versos originais, lá em Portugal existiam adaptações de textos de sucesso. Aqui os autores e parcela significativa do público pertenciam às camadas populares, lá os textos dirigiam-se ao conjunto da sociedade, inclusive letrada. Aqui, os folhetos guardavam fortes vínculos com a tradição oral, no interior da qual criaram sua maneira de fazer versos e lá as matrizes das quais se extraíam os cordéis pertenciam, de longa data, à cultura escrita. Aqui, boa parte dos folhetos tematizava o cotidiano nordestino e lá interessavam mais as vidas de nobres e cavalheiros. Aqui os poetas eram proprietários de sua obra, podendo vendê-la a editores, que por sua vez também eram autores de folhetos. Lá os editores trabalhavam fundamentalmente com obras de domínio público.

Os cordéis portugueses desenham um mundo de convivência harmônica entre classes sociais. As personagens são sempre da nobreza ou filiadas, e os pobres são meritórios e felizes, desde que conheçam seu lugar na sociedade. Nas vezes em que há menção a pobres e ricos isto não é sentido como um desnível, uma desigualdade, já que na estrutura da narrativa todos vivem em harmonia, ajudando-se mutuamente. Há sempre uma exaltação das retidões morais e o verdadeiro e único embate que existe entre os homens é aquele que existe entre o bem e o mal, e o comportamento dos indivíduos sob essas duas ordens cósmicas. Os cordéis lusos, principalmente os enviados ao Brasil, dizem diretamente ou indiretamente a seus leitores que não há por que se preocupar com questões políticas, econômicas ou sociais, já que a preocupação central da vida deve ser a busca do bem e sua luta contra o mal.4

No nordeste brasileiro, ao contrário, a matéria narrativa era calcada na própria realidade nordestina dos séculos XVIII e XIX, quando a criação de gado era a atividade econômica mais importante do sertão, reunindo ao seu redor grande parte da comunidade. Neste contexto, o estado de indignação, lamentação e crítica do cotidiano contamina as histórias. A discussão das

3 ABREU, Márcia. História de cordéis e folhetos. Editora Mercado de livros. I999. 4 ABREU, Márcia. Ibidem. 
diferenças econômicas é constante. Problemas econômicos interferem, também, na construção dos vilões das histórias, pois, além de serem maus, eles têm, em geral, grande fortuna. Associam-se maldade e riqueza, integridade e pobreza. Mas o ponto central das diferenças entre o cordel português, que tende a ser prolixo, e o do nordeste brasileiro, objetivo, é o próprio texto em si.

Como o processo da literatura de cordel iniciou-se no interior das cantorias orais, tão comuns no nordeste desde o princípio do século XVIII, a vida nordestina parece ser o palco e a fonte das narrativas. Os folhetos nordestinos possuem características próprias que permitem a definição clara do que seja esta forma literária, e essa produção de folhetos situa-se na encruzilhada entre a escrita e a oralidade, sendo impossível fixá-la de maneira definitiva em qualquer um desses polos. Os poetas populares nordestinos escrevem como se estivessem contando uma história em voz alta, por isso é evidente o forte vínculo entre o dito e o escrito, mantido nas composições impressas, cuja eficácia é medida pela facilidade de memorização.

É claro que o contato com os cordéis portugueses ajudou a compor esta tradição, aumentando o repertório de situações, temas, personagens, incorporando-os a uma forma poética que já estava evoluindo e se fixando, criada e aperfeiçoada pelos poetas nordestinos, primeiramente no âmbito das cantorias orais e, posteriormente, por meio de folhetos impressos. ${ }^{5}$

A ideia de produzir folhetos foi apenas funcional, pelo seu baixo custo e praticidade, não apresentando em si nenhuma originalidade. Há publicações desse tipo em várias partes do mundo. Até mesmo na Índia editam-se brochuras materialmente idênticas às produzidas no nordeste, elaboradas a partir de folhas de papel jornal dobradas duas vezes ao meio. Obviamente, os folhetos nordestinos não se originaram a partir de uma misteriosa influência hindu. Os folhetos indianos, embora fisicamente idênticos aos nordestinos, possuem conteúdo religioso, narrando histórias míticas da vida dos deuses. Ou seja, assim como existe feijão preto e carne de porco em diversas partes do mundo, mas os usos são diferentes de acordo com o caldo cultural de cada lugar, a ideia de combinar os dois segundo uma preparação específica é peculiar do Brasil. Da mesma forma, compõem-se versos e contam-se histórias em todas as partes do mundo, mas a forma específica das composições nordestinas foi trabalhada e constituída no nordeste brasileiro. ${ }^{6}$

5 As narrativas das cantorias orais e posteriormente sua forma escrita eram compostas dentro de uma forma fixa, uma métrica predeterminada. Foi originalmente essa a grande contribuição lusitana para a literatura de cordel nordestina, pois esse tipo de estrutura poética, essa métrica, era a forma popular do cordel português.

6 ABREU, Márcia. Ibidem. 
De todos os temas que fazem parte da cosmogonia do sertão, o tema que talvez seja o mais típico e característico da miscigenação do nordeste brasileiro, e o seu mosaico cultural, é aquele que gira em torno da figura do boi. Em Portugal, especialmente durante o século XVIII, dominavam as touradas. Este costume foi trazido para o Brasil, mas não se aclimatou. Desenvolveu-se entre nós outro tipo de relação com o boi, as "apartações" e "derrubadas de gado", típicas da região nordestina. Desta intimidade com o gado nascerá o chamado "Giclo do Boi" da literatura de cordel, criação local, sem registro de produções semelhantes entre os portugueses.

No nordeste, a pecuária fixou a população no sertão. Os velhos currais de gado foram os alicerces das futuras cidades e as fazendas marcaram as regiões que futuramente seriam povoadas. Então, das margens do rio São Francisco vieram vaqueiros e ocuparam vastas áreas em Pernambuco e na Bahia. As guerras com os índios no século XVII levaram centenas de homens nas forças de repressão, antecipando a penetração das terras para a criação sistemática de gado. As fazendas se multiplicaram e o gado era o centro de tudo. Este período foi chamado de "Era do couro", pois o couro era a própria essência da economia sertaneja da época. A pecuária dava o sentido de riqueza e força social. A figura máxima era o fazendeiro, com suas cabeças de gado, seus vaqueiros e escravos. A fazenda não exigia tantos braços como o engenho e a lavoura. $O$ trabalho era o mesmo para todos. As pequenas plantações de subsistência e o gado garantiam a funcionalidade do sistema. ${ }^{7}$

O gado de todas as fazendas, no mês de junho, no inverno seco, era criado em comum, nos campos, sem distinção, e era tocado para grandes currais, escolhendo-se sempre a fazenda que tivesse um local de recolhimento maior. Dezenas e dezenas de vaqueiros passavam semanas reunindo todo o gado esparso pelas serras e tabuleiros, e compravam, vendiam e trocavam criações de bichos, como numa verdadeira feira. A reunião de tantos homens e a ausência de divertimentos num ambiente coletivo eram favoráveis a várias atividades que tinham o gado como protagonista. Nas horas vagas, desenvolviam jogos próprios de entretenimento onde realizavam demonstrações de habilidades e perícia no trato com os cavalos e o gado. Algumas reses eram separadas para a "vaquejada", que era como os vaqueiros chamavam a perseguição e derrubada do boi, em velocidade, perseguido pelo boiadeiro e seu cavalo. A "apartação" era outro jogo, cuja ação era identificar o gado de cada patrão dos vaqueiros presentes.

Pela manhã, e mais habitualmente à tarde, corria-se o gado. Só os touros, novilhos e bois fortes participavam do folguedo. Alguns homens, dentro do curral, provocavam os bois famintos e inquietos e depois soltavam o animal

7 GASGUDO, Luís da Câmara. Vaqueiros e cantadores. Editora Itatiaia. I984. 
para fora da porteira. Um vaqueiro mantinha o bicho na direção pretendida, o outro, derrubava o bicho, apanhando-lhe a cauda na mão e puxando com força. Desequilibrado, o boi caía de pernas para o ar. Todos comemoravam o feito, e um ou dois cantadores, dedilhando suas violas, recordavam as apartações e as vaquejadas, transformando os vaqueiros em heróis e celebrizando seus nomes, e glorificando seus cavalos pela valentia. ${ }^{8}$

\author{
Era o povo em demasia, \\ Que não podia contá, \\ Homi muié e menino, \\ Que chegava a negrejá, \\ Só se acreditava bem, \\ Foi quem viu, quem estava lá. ${ }^{9}$
}

O vaqueiro era um símbolo, um documento vivo da continuidade do espírito desbravador, a perpetuidade do hábito, a obstinação de uma herança tradicional. As poesias de vaquejada e apartação eram estritamente locais. Valorizavam sempre a habilidade do vaqueiro, e os cavalos velozes, e as atitudes de assistência diante do boi e sua queda. ${ }^{10}$

Os versos, com o tempo, perderam muito de sua vibração perante o público, pois depois de ouvidos alguns, outros ficaram monótonos, pela uniformidade do assunto, e não despertaram o mesmo interesse e longevidade daqueles que iriam cantar as aventuras dos bois rebeldes em disparadas, em plena liberdade selvagem. Então se contavam histórias de bois indomáveis, misturando-se com fatos cuja oralidade mitificava, pois com o tempo, em vez de narrar a vaquejada, começaram as narrativas de bois, de touros bravos, fugindo em disparadas fantásticas pelos campos em plena liberdade selvagem, fora do alcance dos vaqueiros. $O$ cantador passa a encarnar o animal, descreve o seu orgulho, sua alegria de derrotar os melhores boiadeiros da redondeza. Pela voz do poeta, na maior parte das vezes negro, o animal saúda ironicamente os cavalos, manda

\title{
8 GASGUDO, Luís da Câmara. Ibidem.
}

9 Fabião das queimadas (I848-I928). Poesia de vaquejadas e apartação, descrevendo uma vaquejada na fazenda Potengi Pequeno, município de São Tomé, Rio Grande do Norte, I92I.

Io Este hábito de derrubar o boi, puxando-o pela cauda, é uma variação de outro tipo de procedimento de "derrubada" feita com uma vara de ferrão, bruscamente tocada no flanco do animal, uma espécie de rasteira. A transição da vara de ferrão para a puxada pela cauda parece ter ocorrido no desenvolvimento desta prática e sua técnica de dominação do boi. A queda era motivada por um forte e rápido impulso lateral que o vaqueiro dava, puxando a cauda do bicho. Tudo leva a crer que a vaquejada chamada, queda de rabo, é uma reminiscência das antigas quedas de vara, dos versos populares. 
lembrança aos vaqueiros, e conta sua própria história, de boi fugitivo tornado celebridade. ${ }^{\text {II }}$

Por isso é fácil compreender porque dentre as histórias de cordel no Brasil, as mais apreciadas eram as que contavam a vida de bois valentes e insubmissos, que fugiam, perdiam-se ou resistiam às tentativas de captura, empreendidas por vaqueiros. Essas composições, baseadas em eventos cotidianos, discutiam aspectos cruciais da vida das pessoas, e principalmente do escravo. O cordel de animais é o mais próximo das origens da rica expressão do cordel. Sua abundância no passado e a raridade no presente marcam o predomínio e o declínio da pecuária nordestina. ${ }^{12}$

Em geral, o boi ocupava o papel de narrador, contando sua trajetória de perseguições, afirmando sua determinação de manter-se livre. O foco da narrativa atém-se aos sucessivos confrontos entre perseguidor e perseguido, até o momento da captura, morte, ou desaparecimento sobrenatural do bicho. O herói não era o homem, mas o animal. A curiosidade maior do cordel é a identificação do contador com o seu modelo, o boi. Nenhum vaqueiro era glorificado nessas composições. O homem presente na narrativa representava a ordem, a organização, o respeito às regras, enquanto o boi fugitivo simbolizava a liberdade, a valentia, a perseverança, a habilidade de fugir da opressão. Tanto o poeta como o público se identificavam com o bicho, mesmo sabendo que o fim podia ser a morte. O boi era evocado com nomes próprios, e contava sua história na primeira pessoa, narrando suas andanças, que nada mais eram do que um retrato da dura vida de cada um dos sertanejos. Os mais antigos versos descrevem cenas e episódios da pecuária, o drama e as farsas do gado. Os mais velhos versos são dedicados a bois, touros e vacas. Foram escritos e cantados focando o motivo essencial do trabalho humano da época. ${ }^{13}$

Na linguagem utilizada nos versos, vários termos são do século XVIII, e comuns no sertão daquela época. A quase totalidade dos versos é anônima, e todo sertão reconta a obra sem conhecer seu autor. O poeta sertanejo desaparece transfigurado no boi que fala para a memória das gerações futuras: "Achandome perto da morte, vou contar a minha vida”. O mais antigo registrado é o cordel do Boi Surubim, que é também um dos mais antigos de fato e de maior área de influência no nordeste. No sertão oeste do Rio Grande do Norte, em I9IO, era comum ouvir entre os vaqueiros a expressão: aqui não passa nem o Boi Surubim. Existe uma grande quantidade de versões sobre a origem do nome. Sabemos que Surubim é um rio do Piauí, região que já foi grande produtora de

II CASGUDO, Luís da Gâmara. Ibidem.

I2 ABREU, Márcia. Ibidem.

I3 ABREU, Márcia e SGHAPOCHNIK, Nélson. Cultura letrada no Brasil: objetos e práticas. 
gado nas primeiras décadas do século XIX, mas é também o nome de um peixe azul da região. ${ }^{14}$

Os velhíssimos romances do Boi Espácio, Boi Barroso, Boi Surubim, Vaca do Burel, Boi Mão de Pau, Boi Moleque, Boi Mandingueiro, Boi Misterioso, Boi Pintadinho, tornaram-se famosos e foram mais registrados em locais de menos influência litorânea e mais profundamente adentrados no sertão. $O$ romance do Boi Espácio é de aproximadamente I822, contemporâneo das lutas pela independência no Brasil, o romance do Boi Liso, cerca de I827, o do Boi Surubim de I773. O Rabicho da Geralda é um dos mais tradicionais de todo o sertão, e cita a grande seca de I792. ${ }^{\mathrm{I}}$

Há sempre a presença do fantástico cercando a figura do animal que é glorificado. O cordel "História do Boi Mandingueiro e o Cavalo Misterioso" exemplifica bem os matizes dos cordéis ligados ao gado e ao bestiário do sertão. A própria palavra "Mandingueiro" é ilustrativa das qualidades do boi, suas origens e conexões com a presença do africano na cultura do cordel. Mandingueiro indica originalmente os indivíduos dos Mandingas, raça de negros miscigenada com elementos berberes e etíopes e que sofreram influência maometana. Eram considerados grandes mágicos e feiticeiros. É daí, provavelmente, que vem o sentido hoje associado ao verbo mandingar, que é enfeitiçar. ${ }^{16}$

Os personagens humanos também são característicos e típicos do cordel. A figura sempre presente do rico fazendeiro, os vaqueiros locais, os vaqueiros de outros Estados, o vaqueiro mulato ou índio, de aspecto amedrontador, geralmente o mais hábil entre todos, e o bom moço salvador de família, com tradição no trato com o gado, tendo ainda o ingrediente herdado do cordel português, da jovem moça loira de olhos azuis, que será o prêmio do vaqueiro campeão, como nas antigas competições das justas medievais.

É importante destacar a organização da narrativa. Ela sustenta-se no encadeamento das ações, não havendo nenhuma constituição de cenário, de ambiente, nenhuma descrição de paisagens. A narrativa não abandona jamais o eixo central da trama, não desvia a atenção do leitor para paisagens, fisionomias, estados psicológicos ou acontecimentos paralelos. Com raras exceções, a apresentação dos atributos físicos das personagens tem pequena relevância. ${ }^{17}$ A configuração das personagens baseia-se na apresentação de seus

I4 Çoo-obi, em nhengatu.

I5 CASGUDO, Luís da Câmara. Ibidem.

I6 BUARQUE de Holanda Ferreira, Aurélio. Pequeno dicionário brasileiro da língua portuguesa. I976.

I7 Há descrições mais minuciosas da personagem quando é de origem indígena, insistindo na construção grosseira do seu aspecto, acentuado por alguma deformidade ou cicatriz. 
atributos morais. Não há reação psicológica das personagens. O espaço é pouco caracterizado. O passado é indeterminado, quase atemporal. O tempo e o espaço são categorias que obedecem apenas às necessidades de ação.

Assim constitui-se a gênese que estrutura o cordel de bois. Ênfase na ação, constituição de personagens fortes, sem oscilações de caráter ou de comportamento, criação de um universo maniqueísta, com pouco espaço destinado a personagens e tramas secundárias.

Para melhor exemplificar, contaremos a história do "Boi Mandingueiro". Era uma vez um fazendeiro do Rio Grande do Norte, respeitado pela fama do dinheiro e criador de gado. Ele tinha uma vaca, chamada Endiabrada, muito arisca e indomável. Um dia, estando a dita vaca já velha e esquecida, ela foi encontrada prenha. No momento seguinte, a vaca morreu parindo um bezerro grande e preto como veludo. O bezerro, logo que desmamou, fugiu. Com o tempo, tornouse um boi grande, com chifres descomunais, e de aspecto carrancudo. Foi visto por um vaqueiro que tentou apanhá-lo sem sucesso. O fazendeiro, informado do sucedido, reconhece nas descrições do boi o tal bezerro fujão, e convoca os mais famosos boiadeiros das redondezas para caçá-lo. Logo o boi pega fama de amaldiçoado e demoníaco, pois os vaqueiros não conseguem seguir seu rastro, apesar dos excelentes cavalos, pois o boi preto nasceu para correr na caatinga. Devido aos vaqueiros locais não conseguirem pegar o boi, sua fama espalha-se para outros Estados, atraindo vaqueiros ainda mais célebres.

Chega um vaqueiro mulato da Bahia, zarolho e de fala defeituosa. Pela sua aparência rústica é valorizado, mas após dura perseguição, morre seu cavalo e ele por vergonha, abandona o ofício de boiadeiro para sempre. Então o rico fazendeiro, inconformado com o sucedido, oferece publicamente uma grande soma em dinheiro e a mão de sua filha em casamento, para aquele que pegar o boi. De todos os cantos chegam vaqueiros, velhos e novos, para tentar a sorte com seus maravilhosos cavalos. Mas todos falham, apesar da forte motivação, que é um casamento com a linda Leonor, a loura filha do fazendeiro, com seus olhos azuis, lábios finos corados e a formosura dos seus quinze anos.

Quando tudo parecia perdido, um cavalo misterioso aparece na trama, com características sobrenaturais semelhantes ao do boi feiticeiro. Nasceu de uma velha égua, à meia-noite, preto da cor do carvão. Pertencia a um vaqueiro do Piauí, de ancestral tradição, que ao morrer deixa-a de herança ao seu filho com uma cela feita de couro de lobisomem, mula sem cabeça e bicho que vive e não come. Este cavalo era cheio de segredos e tinha a velocidade do vento. Num determinado dia, Genésio, o filho do falecido vaqueiro, fica sabendo da fama do Boi Mandingueiro. Assim termina a primeira parte do cordel, com suspense e promessas de novas aventuras.

$\mathrm{Na}$ segunda parte, ao ouvir a narrativa do boi tinhoso, o cavalo preto e seu cavaleiro partem para o Rio Grande do Norte. Lá chegando, o cavalo era só 
osso, e não causou muita admiração. Por outro lado, o rapaz Genésio logo teve a simpatia da moça e deixou claro ao fazendeiro sua determinação de pegar o Boi Mandingueiro. A esta altura, seu cavalo era motivo de chacota, pois aparentava estar mais morto que vivo, só pele e osso, tremendo e cambaleando, com as pernas bambas e quase caindo ao chão. Por todos Genésio era tido por louco, querendo pegar o boi maiúsculo com um cavalo moribundo. Preparando-se para a aventura, Genésio acorda o cavalo, que já estava cercado de duzentos urubus e sendo comido por eles. Com forte assobio, Genésio desperta o cavalo, que recobrando o seu vigor ergue-se, agora gordo e forte, com seu corpo descomunal.

Ao longo da narrativa, letreiros fantasmagóricos com frases e pensamentos, aparecem de forma mágica na pele do cavalo e do boi, alternando avisos com ameaças, como se fosse uma espécie de comunicação entre eles, boi e cavalo. A perseguição é implacável e depois de muita luta, o cavalo preto vence o boi preto, que é levado para a fazenda com aboio e tudo no caminho. Um romântico jantar espera na fazenda o moço Genésio e a jovem Leonor. Uma grande festa teve início na fazenda, e efetivou-se o casamento. O Boi Mandingueiro e o Cavalo Misterioso foram colocados num grande cercado, mas logo fugiram e os donos nunca mais os viram.

Tempos depois, notícias são trazidas do estrangeiro, por quatro urubus, mais pretos do que carvão, contando o destino do Boi Mandingueiro, vivendo a apoteose de sua natureza livre e vitoriosa, e do Cavalo Misterioso, punido com o açoite, por ter traído seu irmão boi; Irmão na cor e na liberdade. $\mathrm{O}$ cavalo preto é o próprio duplo do boi, o seu próprio avatar que o persegue. Esta simbologia possui raízes profundas na África, nos sangrentos embates entre os negros na sustentação do tráfico de escravos.

O boi é um símbolo de bondade, de calma, de força pacífica; de capacidade de trabalho e de sacrifício. Na cultura hindu, é associado a uma divindade da morte. No Tibete, o espírito da morte tem cabeça de boi. Entre os gregos, o boi é um animal sagrado. Muitas vezes é imolado em sacrifício a Zeus. O termo "hecatombe" designa um sacrifício de cem bois. Em toda a África do Norte, o Boi é igualmente um animal sagrado, oferecido em sacrifício, ligado a todos os ritos de lavoura e de fecundação da terra. Por causa desse caráter sagrado de suas relações com a maior parte dos ritos religiosos, como vítima ou como sacrificador (quando, por exemplo, abre o sulco na terra) o boi foi também o símbolo do sacerdote. A figura do boi marca a força e a potência, o poder de cavar a terra para receber as chuvas do céu, os seus chifres simbolizam a força conservadora e invencível. ${ }^{18}$

I8 CHEVALIER, Jean e Gheerbrant, Alain. Dicionário de símbolos. José Olímpio Editora. I999. 
O cavalo é associado às trevas, galopante como o sangue nas veias das entranhas da Terra, ou às abissais profundezas do mar. É filho da noite e do mistério. Esse cavalo arquetípico é portador da morte e da vida ao mesmo tempo, ligado ao fogo, destruidor e triunfador, e também à água, nutriente e asfixiante. Por isso os psicanalistas fizeram do cavalo o símbolo do psiquismo inconsciente ou da psique humana. O cavalo representa, também, o instinto controlado, dominado, a mais nobre conquista do homem, entretanto, como não há conquista que seja eterna, sempre reaparece o cavalo tenebroso, que prossegue dentro de nós, sua corrida infernal. O cavalo não é um animal como os outros, ele é montaria, veículo, e seu destino é inseparável ao destino do homem. ${ }^{19}$

Na cultura africana, o cavalo e o cavaleiro fazem uma inversão de papéis, onde o homem possuído pela clarividência torna-se ele próprio o cavalo, para ser montado por um espírito. ${ }^{20} \mathrm{O}$ cavalo instrui o homem, ou seja, a intuição esclarece a razão. Ele ensina os segredos, conduz de maneira justa. O cavalo atinge sempre os pólos de luz e das trevas, e é o condutor desta transição, onde os planos superiores e inferiores se manifestam por seu intermédio. O cavalo passa com igual desenvoltura da noite para o dia, da morte para a vida, da paixão à ação, religa portanto os opostos numa manifestação contínua. Ele é essencialmente manifestação, ele é vida e continuidade acima da descontinuidade de nossa vida e de nossa morte.

A história do Boi Mandingueiro e do Cavalo Misterioso é típica da tradição do cordel, e evidencia o principal aspecto das narrativas cuja figura central é o boi preto, símbolo do escravo e da presença marcante do africano na literatura de cordel, principalmente as mais antigas, dedicadas aos animais falantes, tendo a figura do boi como o próprio negro escravo em busca da liberdade.

Existem evidências da influência marcante de africanos e afro brasileiros em memórias e narrativas contadas em pelejas, desde finais dos oitocentos. São histórias e aventuras sobre animais, em contos narrados na África e também no Brasil, nas tradicionais cantorias do sertão, e em folhetos de literatura oral. Tendo como tema façanha de heróis com seus animais, animais heroicizados, ou "aventuras do reino encantado da bicharada", estas narrativas de folhetos de literatura oral aproximam-se de histórias de memória cantada, que remetem a cantadores africanos que se revestiam de características de temidos animais. As histórias de tradições orais, narradas à noite entre vaqueiros, ao entremear a voz do boi com a de boiadeiros, permite apreender, nessas pelejas sobre animais, as diversidades e desiguais inserções de africanos em terras brasileiras. ${ }^{21}$

I9 CHEVALIER, Jean e Gheerbrant, Alain. Ibidem.

20 Este termo "cavalo" ainda hoje é usado na Umbanda para se referir ao filho-de-santo, que possuído por um espírito, realiza em nome dele uma série de ações rituais, ou de profecia.

2I ABREU, Márcia e SCHAPOCHNIK, Nélson. Cultura letrada no Brasil: objetos e práticas. 
Nos cordéis do chamado ciclo do gado, ao identificarmos o narrador como o "espectro" do próprio boi, herói que encarnando a força e a valentia luta por sua liberdade no sertão, podemos enxergar na saga do boi a epopeia dos africanos escravizados no Brasil, entoada por cantadores de origem ou de descendência africana, entremeando realidade e imaginário. Tais expressões populares apontam, para além de documentos convencionais, o quanto foi longa, conflituosa e complexa a transformação do africano vencido e vendido na África, em escravos para serem comprados no Brasil.

O boi marcou fortemente o imaginário do nordeste, proliferando, por exemplo, nos folguedos de Bumba-meu-boi e em vários folhetos de cordel. A presença do boi foi largamente disseminada entre os povos Bantu, africanos que no período da colheita conduziam um boi estilizado em procissão no meio de cantorias e danças. As cantorias, associadas a festas e pelejas, operavam como vias de acesso a esta gesta dos animais em tradições poéticas orais. O cordel é herdeiro desta oralidade, a partir do momento que grupos populares conquistaram suporte material para impressão e transmissão de palavras cantadas. Os folhetos retomam narrativas de contos, aventuras, romances, preservando, em seus versos, memória de histórias encantadas, do tempo em que os bichos falavam, sentavam à mesa para comer, dançavam, casavam, assombravam e intercruzavam reinos humanos e animais. ${ }^{22}$

Poetas versificaram estas injunções dos reinos humano e animal, narrando visões de mundo, em que animais participavam de experiências sociais. Alguns deles associavam estes tempos ao das histórias contadas por africanos sobre o tempo em que os animais falavam. Estas histórias eram contadas nos pátios, nos terreiros das fazendas escravistas, nos descansos noturnos, quando chegava a vez e a hora do trabalho da memória. Os escravos, cantadores de muitas gerações, tomavam a palavra e o ritmo de seus universos poéticos, narrando aventuras de outros tempos e espaços, quando os animais falavam e conviviam com os homens. Narrativas de africanos, escravos ou ex-escravos, transmitidas na oralidade. Nestas memórias cantadas, todos os viventes eram iguais, e as características dos animais tornavam-se atributos qualificadores dos perfis humanos, no físico, na moral ou no processo mental.

As simbologias animais, com o qual o negro africano se identificava, serviam de instrumento para a expressão sem conflitos. A figura rebelde de um macaco pode identificar a resistência do africano ao trabalho forçado. O tempo em que os bichos falavam pode representar a liberdade, antes de o africano sucumbir à escravidão. Um bicho com a língua cortada pode significar o negro afastado de sua cultura, e simbolicamente reduzido a dimensões 
apenas físicas, aprisionado e oprimido. ${ }^{23}$

$\mathrm{Na}$ perspectiva do conflituoso processo de escravização no Brasil, o universo dos folhetos de cordel produziu imagens referentes a esta não aceitação da condição escrava, na figura do boi preto mágico, misterioso, veloz e livre, quebrando os grilhões do confinamento e da submissão.

As transformações que o romanceiro português experimentou no nordeste do Brasil, em suas interações com as tradições africanas, passaram pelas bocas das negras velhas, que se tornaram, entre nós, as grandes contadoras de histórias. Assim, na pessoa das escravas negras que só faziam contar histórias andando de engenho em engenho, constituiu-se no Brasil uma verdadeira instituição africana. Por seu intermédio, histórias africanas, principalmente de bichos, espalharam-se, tingindo a cultura local.

Essas particularidades culturais que analisamos visam o entendimento da transmissão de culturas orais africanas aqui no Brasil e a dinâmica das interações e sentidos na presença do boi preto na literatura de cordel. Para o enfoque abordado, a partir dos cordéis cujos protagonistas são os bois pretos, e em torno dos rastros da cultura dos afro-descendentes no Brasil, é importante destacar que grupos constituídos por expressões de oralidades interpretavam, orientavam e exercitavam transmissões de suas experiências vividas a partir da lógica de mentalidade proverbial, suscetíveis a diversas leituras e sentidos. ${ }^{24}$

Este é um texto de síntese e reflexão que ao circular pelas obras já citadas, nos introduz na brilhante obra historiográfica destes autores - Márcia Abreu, Nelson Schapochnik, Luiz da Câmara Cascudo e Durval Muniz de Albuquerque Júnior - de onde pude concluir raciocínios que me levaram a decifrar um pouco desta cantiga, que atemorizava e ao mesmo tempo encantava, embalando o sono de crianças.

Boi, boi, boi, boi da cara preta, pega essa menina que tem medo de careta. ${ }^{25}$

23 ABREU, Márcia. História de cordéis e folhetos. Edit. Mercado de Letras. I999.

24 ABREU, Márcia e SCHAPOCHNIK, Nélson. Cultura letrada no Brasil: objetos e práticas. Edit. Mercado de Letras.

25 Cantiga popular anônima, atribuída à região do Maranhão, por volta do século XIX. Há controvérsias quanto a sua região de origem e época. 


\section{Referências Bibliográficas}

CASGUDO, Luís da Câmara. Vaqueiros e cantadores. Editora Itatiaia. I984.

ABREU, Márcia. História de cordéis e folhetos. Editora Mercado de Letras. I999.

ROSA, João Guimarães. Sagarana, Conversa de Bois, Editora Universal. I946.

ABREU, Marcia e SCHAPOCHNIK, Nelson. Cultura letrada no Brasil: objetose práticas. Editora Mercado de Letras. 2005.

BUARQUE de Holanda Ferreira, Aurélio. Pequeno dicionário brasileiro da língua portuguesa. 1976.

ALBUQUERQUE Jr., Durval Muniz. A invenção do nordeste e outras artes.

Editora Cortez. 2009.

GHEVALIER, Jean e Gheerbrant, Alain. Dicionário de símbolos. José Olímpio Editora. I999.

Ivan Luiz Chaves Feijó é graduando em História pela USP.

E-mail: ivan.feijo@usp.br 